\title{
Custo de produção e análise de eficiência econômica de feijões especiais em Goiás
}

\author{
Cost of production and analysis of economic efficiency of special beans in Goiás
}

\author{
Waleska Maria Fernandes Lima ${ }^{a}$ \\ Alcido Elenor Wander ${ }^{b}$ \\ Gabriel da Silva Medina ${ }^{\mathrm{c}}$
}

\begin{abstract}
Resumo: O presente estudo visa verificar a viabilidade agroeconômica da produção de grãos especiais de feijão na terceira safra, no estado de Goiás. Para tanto, foram estimados os custos de produção dos cultivares de grãos especiais BRS Embaixador, BRS Executivo e BRS, além do cultivar de grão carioca BRS Estilo. Foram utilizados coeficientes de eficiência econômica (renda líquida, ponto de nivelamento, produtividade total dos fatores e taxa de retorno, entre outros). Identificamos que a viabilidade agroeconômica é apresentada apenas no cultivar BRS Embaixador que ao preço de venda considerado, gerou renda líquida de R\$ 650,19 e taxa de retorno de $11 \%$.
\end{abstract}

Palavras-chave: Feijão; Grãos Especiais; Custos de produção; Eficiência Econômica. Classificação JEL: QI; Q11

\begin{abstract}
The present study aims to verify the agroeconomic viability of the production of special bean grains in the third harvest, in the state of Goiás. For this purpose, the production costs were estimated for special grain varieties BRS Embaixador, BRS Executivo, and BRS Ártico, in addition to the Brazilian commercial reference BRS Estilo. Economic efficiency coefficients (net income, break-even point, total factor productivity, and rate of return, among others) were used. We identifield that only the variety BRS Embaixador was agroeconomically viable, generating a net income of $\mathrm{R} \$ 650.19 /$ ha and a rate of return of $11 \%$.
\end{abstract}

Keywords: Beans; Special Grains; Production costs; Economic Efficiency.

\footnotetext{
${ }^{a}$ Mestra em Agronegócio no PPAGRO pela Universidade Federal de Goiás. E-mail: waleskafernandes1@hotmail.com

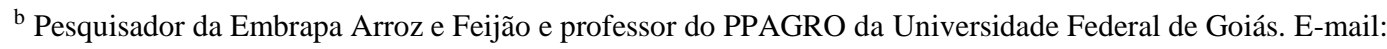
alcido.wander@embrapa.br

${ }^{\mathrm{c}}$ Professor do PPAGRO da Universidade Federal de Goiás. E-mail: gabriel.silva.medina@ gmail.com
} 


\section{Introdução}

No Brasil, o feijão carioca domina as áreas de cultivo, sendo preferência dos produtores e dos consumidores. Este grão é cultivado nas três safras (águas, seca e inverno) e, por isso, é amplamente difundido por todo o território nacional. A predominância dos grãos do tipo carioca causa problemas no mercado de feijões, afetando desde os produtores até o consumidor final.

Como resultado do domínio do tipo carioca nos campos, o mercado de grãos tem apresentado significativas oscilações de preços pagos ao produtor e, consequentemente, elevações de preços repassados ao consumidor decorrente da falta do produto no mercado nacional. Dados da Companhia Nacional de Abastecimento (Conab) (CONAB, 2019) demonstram que, no Brasil, foi possível verificar uma redução de 17,3\% na produção de feijão em janeiro de 2019, em comparação à safra de 2017/2018. As chuvas abundantes no leste de Goiás, entre novembro e dezembro de 2018, acarretaram prejuízos nas lavouras de feijão, que já estavam em processo de floração e enchimento de grãos. Com isto, o rendimento médio esperado também apresentou redução de $15,9 \%$ em relação à safra anterior. No estado de Goiás, a Conab (2019) estimou que a maior parte das áreas de feijãocomum será cultivada em período de segunda safra, já que a primeira safra sofreu com a redução significativa do regime de chuvas. Assim sendo, já se projeta uma produção menor do que a obtida na safra 2017/2018.

Os problemas de mercado do feijão carioca poderiam ser resolvidos, em parte, se houvesse uma diversidade na produção, com o cultivo de feijão de grãos especiais. Os grãos especiais possuem atributos de qualidade desejados pelos mercados internacionais, como tamanhos e formatos específicos de grãos, ao contrário do tipo carioca que é produzido e consumido apenas no Brasil.

Estudos publicados sobre grãos especiais destacam mais a questão de produtividade e de oferta/demanda. A análise das questões econômicas de cultivo destes grãos é ainda uma lacuna nas pesquisas científicas. É este fato que motivou este estudo a focalizar a análise nos custos de produção e na eficiência econômica de grãos especiais de feijão, considerando assim, tanto o aumento da exportação quanto a redução da importação.

Neste contexto, com a baixa diversidade da produção de feijão, o objetivo deste estudo é verificar a viabilidade agroeconômica da produção dos grãos especiais em Goiás, na terceira safra, mediante a construção dos custos de produção dos cultivares selecionados, com análises dos coeficientes de eficiência econômica. A hipótese é de que a produção de grãos especiais de feijão é agroeconomicamente viável. Assim, se viáveis, os feijões especiais podem contribuir para uma maior diversificação do mercado nacional.

Este artigo está dividido em cinco seções, incluindo esta introdução. Na segunda seção, apresentamos o referencial teórico do estudo, analisando os custos de produção e os indicadores de eficiência econômica. Na terceira seção, explanamos a metodologia empregada neste estudo, incluindo a escolha dos cultivares. Na quarta seção, detalhamos os resultados encontrados e suas respectivas análises/discussões. Por fim, na última seção, organizamos algumas considerações finais. 


\section{Referencial Teórico}

\subsection{Custos de produção}

A teoria dos custos tem como princípio a maximização dos lucros e concomitantemente a minimização dos custos. Para que este resultado seja atingido é necessário responder a três questionamentos: "o que produzir?"; "como produzir?"; e "quanto produzir?". Deduzimos destas questões que para obter uma eficiência econômica satisfatória, com lucros maiores, deve-se, primeiramente, definir qual atividade ou qual combinação de atividades serão empregadas, depois, quais métodos serão praticados, bem como a quantidade de insumos, maquinaria, mão de obra, entre outros, além de quanto se utilizará de determinado componente da produção, a fim de alcançar maior produtividade (DOLL; ORAZEM, 1984).

Tais questionamentos podem ser respondidos com base na formulação de orçamentos. Kay et al. (2014) citam que orçamentos de empreendimentos são um conjunto das rendas e despesas de determinada atividade, com a finalidade de avaliar sua lucratividade e construir um plano completo da atividade agropecuária que se deseja colocar em prática e, consequentemente, possibilita o cálculo dos custos de produção.

Compreende-se por custo de produção todos os gastos utilizados no processo produtivo, sendo eles o conjunto de recursos, operações, insumos e serviços. O custo de produção tem o propósito de determinar o custo mínimo por unidade produzida, a partir dos valores dos componentes da produção, e compará-lo com o preço do produto final. Além disso, é possível comparar os níveis de desempenho entre diferentes sistemas de produção (GUIDUCCI et al., 2012).

O conhecimento do custo de produção se faz necessário e fundamental para a tomada de decisão do produtor rural. Com base nos resultados será possível estimar a viabilidade econômica dos sistemas de produção e decidir qual a melhor opção a ser empregada na propriedade, de forma eficiente e com o melhor retorno econômico (MENEGATTI, 2006). Os objetivos do custo de produção podem ser vistos com maior detalhe em Santos e Marion (1996, p. 33),

a) auxiliar a administração na organização e controle da unidade de produção, revelando ao administrador às atividades de menor custo, as mais lucrativas, as operações de maior e menor custo e as vantagens de substituir umas pelas outras;

b) permitir uma correta valorização dos estoques para a apuração dos resultados obtidos em cada cultivo ou criação;

c) oferecer bases consistentes e confiáveis para projeção dos resultados e auxiliar o processo de planejamento rural, principalmente quando o administrador precisa decidir o que plantar, quando plantar e como plantar;

d) orientar os órgãos públicos e privados na fixação de medidas, como garantia de preços mínimos, incentivo à produção de determinado produto em escala desejada, estabelecimento de limites de créditos etc.

Mesmo com os objetivos definidos, a mensuração do custo de produção difere de uma propriedade para outra. Godinho et al. (2001) mencionam sobre a dificuldade em 
estabelecer um cálculo padrão para o custo de produção das atividades agrícolas em virtude das características de cada propriedade, como condições climáticas, tipo de solo, tamanho da área, maquinário, nível de tecnologia, questões administrativas, entre outras. Isto explica as diferenças entre os custos de produção obtidos em propriedades com as mesmas atividades. A escolha da metodologia para o cálculo do custo de produção dependerá do modelo que mais se aproxima da forma como o produtor incorpora seus componentes de custos.

De acordo com Martins (2006), os custos são classificados conforme sua dinâmica, em fixos e variáveis e, de acordo com sua alocação com o produto ou serviço, em diretos e indiretos.

Os custos variáveis se diferem dos custos fixos em razão da dependência do volume de produção, ou seja, os custos variáveis dependem da quantidade produzida, enquanto os custos fixos se mantêm inalterados independente da produção.

Em relação aos custos diretos e indiretos estes são definidos conforme a identificação. Custos diretos são aqueles aplicados diretamente no produto ou serviço como, por exemplo, o salário de funcionários. Já, os custos indiretos são todos aqueles que não estão diretamente relacionados com o produto ou serviço, ou seja, são alocados aos produtos ou serviços como, por exemplo, a energia elétrica. Neste sentido, o custo com a eletricidade passa a fazer parte do custo do produto, pois se fosse dessa forma, não seria possível viabilizar a produção ou o serviço (VIEIRA, 2013). Assim, pode-se dizer que custos são recursos aplicados pela empresa para se atingir um objetivo, podendo variar de acordo com sua aplicação.

\subsection{Indicadores de eficiência econômica}

Alves (2007) conceitua a eficiência como a menor relação custo/benefício para alcançar os resultados desejados, com o menor uso de recursos para gerar uma quantidade superior de produção. A eficiência pode ser enquadrada em dois tipos: eficiência econômica e eficiência técnica ou física. A primeira refere-se ao valor por unidade de recurso e é dependente da eficiência física, dos preços dos produtos e preços dos insumos.

Já a eficiência física refere-se à capacidade de obter o máximo de produção de acordo com os recursos disponíveis, ou seja, preocupa-se com a velocidade que os insumos são convertidos em cultivos (KAY et al., 2014). Em uma análise de viabilidade econômica, verificar o quanto uma atividade é eficiente ou não, é indispensável para a tomada de decisões pelo produtor, sendo a análise de eficiência econômica a ideal para determinar o quanto de cada fator da produção será utilizado, além de contribuir no planejamento do custo de produção que maximizará os lucros.

A análise de eficiência econômica de uma atividade permite ao produtor conhecer os resultados financeiros obtidos dos fatores de produção, podendo localizar os pontos que precisam ser melhorados para que se alcance o sucesso da atividade. Realizada através do cálculo dos indicadores de eficiência econômica, esta é uma importante ferramenta para a tomada de decisão. Esses indicadores mensuram, financeiramente, a dinâmica da atividade 
(LOPES; CARVALHO., 2002). Guiducci et al. (2012) trazem como indicadores de eficiência econômica: a renda líquida $(\mathrm{RL})$, o ponto de nivelamento $(\mathrm{PN})$, a produtividade total de fatores (PTF) e a taxa de retorno (TR). Estes indicadores econômicos serão abordados a seguir.

\subsubsection{Renda líquida ( $R L)$}

Conceitualmente, muitos autores como Martin et al. (1998), Oliveira et al. (2005) e Tsunechiro et al. (2006) utilizam o que foi proposto por Lazzarini Neto (1995) em Controle da Produção e Custos. Assim, conceituam a renda líquida como o lucro operacional, que constitui a diferença entre a receita bruta e o custo total por hectare. Em outras palavras, Guiducci et al. (2012) conceituam a renda líquida como a remuneração obtida pela diferença entre a receita total e as despesas do sistema de produção, podendo ser estimada por unidade de área ( $\mathrm{R} \$ / \mathrm{ha}$ ) ou por unidade produzida ( $\$ / \mathrm{sc} .60 \mathrm{~kg}$ ) (SILVA et al., 2012).

Araújo et al. (2012) citam que a renda líquida ou o lucro operacional mede a lucratividade da atividade a curto prazo, possibilitando conhecer as condições financeiras e operacionais da atividade agropecuária. O resultado tem o intuito de mostrar se existe ou não estabilidade na atividade, sendo que o valor da renda líquida deve, no mínimo, cobrir os gastos com a produção, os quais são: insumos, maquinaria, mão de obra, despesas financeiras, entre outros (GUIDUCCI et al., 2012). Para o cálculo da renda líquida é fundamental uma mensuração detalhada de todas as receitas e despesas, para que as decisões não sejam distorcidas e o produtor não se baseie em informações ruins para as decisões futuras. Conhecer detalhadamente os recursos físicos, financeiros e humanos pode fazer a diferença entre obter uma renda líquida satisfatória ou não, ou melhor, se a atividade gerará lucro ou prejuízo (KAY et al., 2014).

\subsubsection{Ponto de nivelamento (PN)}

Guiducci et al. (2012) conceituam o ponto de nivelamento, conhecido também como ponto de equilíbrio, como o nível de rendimento em que a renda total se iguala aos custos totais em função de um determinado preço de venda. Da mesma forma, Lopes e Carvalho (2002) e Oaigen et al. (2006) afirmam que é o nível mínimo de produção para que a atividade não gere prejuízos. Lopes e Carvalho (2002) ainda apresentam que o ponto de nivelamento é a quantidade física a ser produzida para que o valor seja igual ao total de custos.

Segundo Sprott (1998) apud Oaigen (2006), o ponto de equilíbrio contribui para que o produtor saiba decidir sobre o manejo no presente e no futuro e, consequentemente, identifique o preço mínimo de venda do produto para cobrir todos os custos. Lopes e Carvalho (2002) e Kay et al. (2014) mostram que para saber o ponto de equilíbrio da atividade é necessário conhecer a remuneração do capital, o custo variável unitário e o preço médio do produto no mercado. 


\subsubsection{Produtividade total de fatores (PTF)}

A produtividade total de fatores mostra a rentabilidade do investimento e o quanto é eficiente o sistema de produção. A produtividade total dos fatores (PTF) é a parte da produção não explicada pela quantidade de insumos usados na produção. Como tal, seu nível é determinado pela eficiência e intensidade com que os insumos são utilizados na produção. O crescimento da PTF é geralmente medido de forma residual, ou seja, como bem explicam Barbosa Filho, Pessôa e Veloso (2010, p. 99), trata-se da "porção do produto não explicada pelo capital físico, capital humano e pela quantidade de horas trabalhadas". Logo, denota-se a taxa de crescimento da produção agregada, a taxa de crescimento do capital agregado, a taxa de crescimento da mão de obra agregada e o capital social.

\subsubsection{Taxa de retorno (TR)}

Para Lima et al. (2016), a decisão de investimento é, provavelmente, uma das decisões mais difíceis e importantes da administração financeira. De acordo com Gitman (2010), se encaixam como investimento de capital (de longo prazo) as atividades de pesquisa e desenvolvimento, os programas de desenvolvimento de novos produtos ou serviços, as atividades de exploração, os custos referentes à formação de executivos e o desenvolvimento de anais de distribuição confiáveis. Portanto, se configuram como investimento de capital todos aqueles investimentos que são realizados com o intuito de se obter benefícios futuros.

A taxa de retorno resulta na quantidade de retorno do capital investido, ou seja, em quanto tempo o investimento com o sistema de produção se transforma em renda líquida. Neste indicador, pode-se depreender a taxa média de retorno (TMR), que é a divisão do lucro líquido médio anual estimado pelo valor médio (ou total) do investimento durante a vida útil do projeto (RESENDE; SIQUEIRA, 2004). Além disso, é possível calculara taxa interna de retorno (TIR), definida como a taxa "pela qual um investimento é recuperado por meio dos rendimentos auferidos de um projeto" (SOLOMON, 1973, p. 177).

\section{Metodologia}

\subsection{Escolha dos cultivares}

Para a análise da viabilidade agroeconômica dos feijões especiais em Goiás, na terceira safra, foram escolhidas os cultivares da Embrapa: BRS Embaixador (tipo comercial vermelho escuro grande - DRK), BRS Executivo (tipo de grão comercial rajado graúdo Cranberry) e BRS Ártico (tipo comercial branco). Para comparações utilizamos o cultivar do feijão carioca - BRS Estilo - cultivar mais plantado atualmente no Brasil. As características de cada cultivar podem ser consultadas em Embrapa (2017a). 
A utilização de dados da terceira safra é devido ao cultivo dos feijões especiais que, em Goiás, é realizado apenas na safra de inverno, com irrigação. Esses cultivares ainda não estão adaptados para outras épocas de cultivo (EMBRAPA, 2017a).

\subsection{Custos de produção}

A análise dos custos de produção foi fator fundamental para o desenvolvimento desta pesquisa, já que é a base para o cálculo da eficiência econômica, o que justifica a elaboração da planilha de custos. As estimativas dos custos de produção foram baseadas em modelo de planilha do sistema de produção de feijão irrigado do cultivar BRS Estilo, disponibilizada pela Embrapa Arroz e Feijão (EMBRAPA, 2017). A planilha é referente ao sistema de produção de feijão irrigado, em sistema de plantio direto, indicada para Goiás, Distrito Federal, Mato Grosso, Tocantins, Minas Gerais e São Paulo. O custo de produção é referente ao mês de abril de 2017, com valor de $\mathrm{R} \$ 130,00$ por saca de $60 \mathrm{~kg}$.

Como os grãos especiais de feijão carecem de dados disponíveis, adaptou-se a tabela do feijão carioca irrigado, BRS Estilo, com os coeficientes técnicos que diferem na produção dos grãos especiais. Essa adaptação se deu por meio de informações de produtores de feijões especiais, também na terceira safra, em Goiás ${ }^{1}$.

Para a análise de viabilidade agroeconômica do sistema de produção foram considerados os preços dos fatores de produção em vigor no mês de abril de 2018, época de preparação para a safra irrigada. Além disso, o preço de venda do produto final considerado foi aquele em vigor no mês de setembro de 2018, época da colheita da terceira safra. Como a planilha do BRS Estilo, disponibilizada pela Embrapa, está com valores dos fatores de produção em vigor no mês de abril/2017, os valores foram deflacionados utilizando o IGP-M² para abril/2018.

A produtividade média considerada para a BRS Estilo foi aquela divulgada no portfólio de cultivares de feijão da Embrapa, 52 sacas ha ${ }^{-1}$, para lavouras comerciais (EMBRAPA, 2017). Para os grãos especiais, como não há dados representativos de lavouras comerciais, foram utilizadas produtividades estimadas a partir da comparação entre os valores de potencial produtivo, conforme o portfólio de cultivares de feijão da Embrapa, e a produtividade comercial para grãos cariocas, assumindo a mesma diferença relativa entre o teto produtivo e a lavoura comercial dos grãos cariocas para os grãos especiais, como mostra o quadro 1.

\footnotetext{
${ }^{1}$ Informações adquiridas através de contatos (telefones, e-mails).

${ }^{2}$ IGP-M para abril//2018 = 1,007572.
} 
Quadro 1: Potencial produtivo e produtividade comercial dos cultivares BRS Estilo, BRS Embaixador, BRS Executivo e BRS Ártico.

\begin{tabular}{|c|c|c|}
\hline Cultivar & $\begin{array}{l}\text { Potencial Produtivo } \\
\text { (sc. de } 60 \mathrm{~kg} \mathrm{ha}^{-1} \text { ) }\end{array}$ & $\begin{array}{c}\text { Produtividade } \\
\text { Comercial } \\
(\text { sc. de 60kg ha-1) } \\
\end{array}$ \\
\hline BRS Estilo (feijão carioca) & 66,85 & 52,00 \\
\hline $\begin{array}{c}\text { BRS Embaixador (feijão vermelho } \\
\text { escuro) }\end{array}$ & 51,88 & 40,35 \\
\hline $\begin{array}{c}\text { BRS Executivo (feijão rajado - } \\
\text { Cranberry) }\end{array}$ & 31,60 & 24,58 \\
\hline $\begin{array}{c}\text { BRS Ártico (feijão branco com ciclo } \\
\text { semiprecoce) }\end{array}$ & 44,62 & 34,71 \\
\hline
\end{tabular}

Fonte: Adaptado de Embrapa (2017a).

Determinados os custos de produção de cada cultivar, foram analisados os componentes de produção, os quais são: insumos, operações com máquinas, irrigação, serviços com mão de obra, pós-colheita (frete e armazenamento) e custos adicionais $\left(\right.$ Proagro $^{3}$, assistência técnica, juros e INSS). Essa análise tem o objetivo de mensurar qual componente mais onera o custo de produção.

\subsection{Indicadores de eficiência econômica}

Para determinar os indicadores de eficiência econômica, com o objetivo de auxiliar o produtor na tomada de decisão, foram estimados a renda líquida (RL), o ponto de nivelamento (PN), a produtividade total dos fatores (PTF) e a taxa de retorno (TR), de cada cultivar.

\subsubsection{Renda líquida ( $R L)$}

A renda líquida é o resultado da receita total ou receita bruta menos o custo total da produção, sendo calcula a partir da seguinte fórmula:

$$
R L=\text { Receita total }- \text { Custo total (1) }
$$

Ressalta-se que se o resultado for positivo, conclui-se que a atividade é estável, possui possibilidade de expansão e de permanência no longo prazo. Com o resultado igual a zero, a atividade estará no ponto de equilíbrio. Mas, com o resultado da renda líquida negativo, a atividade apresenta um problema de descapitalização, mesmo que suporte $o$ custo de produção por um determinado período (LOPES; CARVALHO, 2002).

\footnotetext{
${ }^{3}$ Proagro - Programa de Garantia da Atividade Agropecuária
} 


\subsubsection{Ponto de nivelamento (PN)}

O ponto de nivelamento resulta da divisão do custo total pelo preço de venda do produto, conforme apresenta a fórmula a seguir:

$$
P N=\frac{\text { Custo total }}{\text { Preço do produto }}
$$

O resultado maximiza a renda líquida e possibilita a continuidade da atividade no longo prazo. Caso a atividade produza abaixo do nível gerado, resultará em renda líquida negativa, impossibilitando seu sucesso (GUIDUCCI et al., 2012).

\subsubsection{Produtividade total de fatores (PTF)}

A produtividade total de fatores é dada pela razão entre a receita total e o custo total, sendo que o resultado deve ser no mínimo igual a um, para que a atividade se mantenha produtiva. Nesta pesquisa consideramos a seguinte fórmula:

$$
P T F=\frac{\text { Receita total }}{\text { Custo total }}
$$

Desta forma, quanto maior o resultado da produtividade total de fatores, melhor é o rendimento da atividade (GUIDUCCI et al., 2012).

\subsubsection{Taxa de retorno (TR)}

A taxa de retorno é obtida pela razão da renda líquida pelo custo total, mostrando o quanto uma unidade monetária gasta na atividade se converte em renda líquida, conforme demonstra a fórmula a seguir.

$$
T R=\frac{\text { Renda líquida }}{\text { Custo total }}(4)
$$

Neste sentido, pode-se comparar qual atividade apresenta maior ou menor retorno, possibilitando uma escolha mais rentável ao produtor (GUIDUCCI et al., 2012).

\section{Resultados e discussões}

\subsection{Análise dos custos de produção e coeficientes técnicos}

\subsubsection{Sistema de produção com BRS Estilo}

O custo de produção do sistema irrigado do BRS Estilo, em Goiás, foi estabelecido conforme as fases de implantação e manejo da cultura. O custo médio, por hectare, foi de 
$\mathrm{R} \$ 4.562,14$, equivalente a $\mathrm{R} \$ 44,60$ por saca de $60 \mathrm{~kg}$. Os valores dos componentes da produção e equivalência do produto, em saca de $60 \mathrm{~kg}$, estão apresentados na tabela 1 .

Conforme verifica-se, na tabela 1 , o custeio do pré-plantio, que compreendeu a aplicação de calcário, terraceamento para conservação do solo, dessecação para limpeza da área, valor de mão de obra e operações com máquinas, totalizou em $\mathrm{R} \$ 403,84$, por hectare. Representa 8,86\% do custo total do sistema de produção e equivale a $R \$ 3,95$ por saca de $60 \mathrm{~kg}$. Para a realização do plantio foram gastos $\mathrm{R} \$ 1.036,31$, por hectare, valor equivalente a $\mathrm{R} \$ 10,13$ por saca de $60 \mathrm{~kg}$, representando $22,72 \%$ do custo total de produção do sistema. O plantio compreende o tratamento de sementes, adubação com NPK, operações com máquinas, mão de obra e sementes.

Tabela 1: Custo de produção de feijão-comum por hectare, com o cultivar BRS Estilo, na $3^{\text {a }}$ safra, em Goiás, safra 2018.

\begin{tabular}{c|c|c|c}
\hline \hline Insumos/Operações/Serviços & $\begin{array}{c}\text { Custo atual } \\
\left(\mathbf{R} \$ \mathbf{. h a} \mathbf{-}^{-\mathbf{1}}\right)\end{array}$ & $\begin{array}{c}\text { Participação } \\
\mathbf{( \% )}\end{array}$ & $\begin{array}{c}\text { Equivalência } \\
(\mathbf{s c . 6 0} \mathbf{~ k g})\end{array}$ \\
\hline Calagem & 176,93 & 3,88 & 1,73 \\
\hline Terraceamento & 32,65 & 0,72 & 0,32 \\
\hline Dessecação & 194,26 & 4,26 & 1,90 \\
\hline Plantio & $1.036,31$ & 22,72 & 10,13 \\
\hline Tratos Culturais & $1.639,49$ & 35,94 & 15,35 \\
\hline Colheita & 980,17 & 21,48 & 9,58 \\
\hline Pós-colheita & 250,97 & 5,50 & 2,45 \\
\hline \hline Custos Financeiros Adicionais & 251,38 & 5,51 & 2,46 \\
\hline CUSTO TOTAL & $\mathbf{4 . 5 6 2 , 1 4}$ & $\mathbf{1 0 0 , 0 0}$ & $\mathbf{4 4 , 6 0}$ \\
\hline
\end{tabular}

Fonte: Elaboração própria.

Notas: Com base no preço (FOB) recebido pelo produtor de feijão, em Goiás, pela saca de $60 \mathrm{~kg}$, em setembro de $2018=\mathrm{R} \$ 102,30$. Com base nos preços médios de fatores de produção recebidos pelos produtores em Goiás, na primeira semana do mês de abril de 2018.

Nos tratos culturais ou a condução da lavoura, que são as atividades para controle de formigas, plantas daninhas, pragas e doenças, adubação de cobertura, irrigação, mão de obra e operações com máquinas, foram gastos $\mathrm{R} \$ 1.639,49$, por hectare, do total do custo de produção do sistema. Este valor representa 35,94\% do valor total, ou seja, é equivalente a $\mathrm{R} \$ 15,35$ por saca de $60 \mathrm{~kg}$.

A colheita foi mecanizada, totalizando juntamente com a mão de obra e a quantidade de sacaria, $\mathrm{R} \$ 980,17$ por hectare. Este custo representa $21,48 \%$ do custo total de produção do sistema ou valor equivalente a $\mathrm{R} \$ 9,58$ por saca de $60 \mathrm{~kg}$. Para a pós-colheita, que compreende o transporte da produção da propriedade ao armazém e o armazenamento dos grãos, foram gastos $\mathrm{R} \$ 250,97 /$ há, ou seja, $\mathrm{R} \$ 2,45$ por saca de $60 \mathrm{~kg}$ ou $5,50 \%$ do custo total do sistema de produção. Os custos adicionais financeiros totalizaram $\mathrm{R}$ \$ 251,38/há. Nestes custos estão incluídos Proagro, assistência técnica, juros e INSS, representando $5,51 \%$ ou valor equivalente a $\mathrm{R} \$ 2,46$ por saca de $60 \mathrm{~kg}$, do custo total. 
O custo total por hectare verificado nesta pesquisa $(\mathrm{R} \$ 4.562,14)$ foi bem acima do que foi verificado na pesquisa de Silveira (2015), que apontaram um custo total médio por hectare de $\mathrm{R} \$ 1.600,23$. Todavia, um resultado semelhante pode ser verificado em relação a maior demanda de insumos nos tratos culturais, sendo separada na pesquisa dos autores a despesa com defensivos e fertilizantes.

$\mathrm{Na}$ Tabela 2, é possível verificar os componentes de custo do sistema de produção com a cultivar BRS Estilo.

\section{Tabela 2: Custos dos componentes do processo produtivo de feijão-comum, com o} cultivar BRS Estilo, por hectare, na $3^{\mathrm{a}}$ safra, em Goiás, safra 2018.

\begin{tabular}{l|c|c}
\hline \hline \multicolumn{1}{c|}{ Componentes da Produção } & Custo Atual $\left(\mathbf{R} \mathbf{\$ . h a ^ { - 1 }}\right)$ & Participação (\%) \\
\hline Insumos & $2.046,67$ & 44,86 \\
\hline Operações com máquinas & $1.561,73$ & 34,23 \\
\hline Irrigação & 302,27 & 6,63 \\
\hline Serviços com mão-de-obra & 149,13 & 3,27 \\
\hline Custos adicionais financeiros & 251,38 & 5,51 \\
\hline Pós-colheita & 250,97 & 5,50 \\
\hline CUSTO TOTAL & $\mathbf{4 . 5 6 2 , 1 4}$ & $\mathbf{1 0 0 , 0}$ \\
\hline \hline
\end{tabular}

Fonte: Dados da pesquisa.

A partir da tabela 2, é possível verificar entre os custos dos componentes do processo produtivo de feijão-comum com a cultivar BRS Estilo, que os insumos apresentam maior representatividade, totalizando $\mathrm{R} \$ 2.046,67$, o que corresponde a 44,86\% do custo de produção. O segundo componente que mais onerou o custo total do sistema de produção foram as operações com máquinas $(34,23 \%)$, seguido pela irrigação $(6,63 \%)$ e, com praticamente o mesmo valor, os componentes da pós-colheita e serviços com mão de obra, representando $5,50 \%$ do custo do sistema de produção.

Resultado semelhante foi verificado na pesquisa de Silva e Wander (2015), que também identificaram os insumos como responsáveis pela maior demanda de custos nas safras de inverno ( $3^{\mathrm{a}}$ Safra), considerando a média dos quatro anos que analisaram (de 2011-2014). Ambos - Silva e Wander (2015) - apontaram que os insumos são responsáveis por $60,81 \%$ do custo total, assim como os custos com máquinas, que representam $25,10 \%$ dos custos totais.

Para uma visão mais detalhada destes custos com insumos, verificamos os custos demandados com cada tipo de insumo. Estes dados estão na tabela 3, com seus respectivos valores e participação. 
Tabela 3: Custos dos insumos do processo produtivo de feijão-comum, com o cultivar BRS Estilo, por hectare, na $3^{\text {a }}$ safra, em Goiás, safra 2018.

\begin{tabular}{l|c|c}
\hline \multicolumn{1}{c|}{ Insumos } & Custo Atual $\mathbf{( R \$ . \mathbf { h a } ^ { - \mathbf { 1 } } )}$ & Participação (\%) \\
\hline Agrotóxicos & 766,05 & 37,43 \\
\hline Fertilizantes e Corretivos & 730,49 & 35,70 \\
\hline Sementes & 392,95 & 19,20 \\
\hline Sacarias & 157,18 & 7,68 \\
\hline CUSTO TOTAL & $\mathbf{2 . 0 4 6 , 6 7}$ & $\mathbf{1 0 0 , 0 0}$ \\
\hline \hline
\end{tabular}

Fonte: Dados da pesquisa.

Dentre os insumos, os componentes que mais oneram o custo de R \$2.046,67/há, são os agrotóxicos, que representam $37,43 \%$, em seguida, os fertilizantes e corretivos, $35,70 \%$, depois, as sementes, $19,20 \%$ e, por fim, as sacarias, 7,68\%. Similar a estes percentuais, Silva e Wander (2015) verificaram os defensivos como maior participante dos custos do processo produtivo neste tipo de cultivar, em safra de inverno $(20,17 \%)$, seguido pelos fertilizantes e corretivos $(19,85 \%)$, pelas sementes com $(11,36 \%)$ e pelas sacarias $(3,35 \%)$. Ressalta-se que essa forma de plantio apresentou o menor custo em relação às demais formas de cultivar.

\subsubsection{Sistema de produção com BRS Embaixador}

O custo de produção do sistema irrigado com a cultivar BRS Embaixador, em Goiás, foi estabelecido conforme as fases de implantação e manejo da cultura. O custo médio, por hectare, foi de $R \$ 5.717,07$, equivalente a $R \$ 36,23$ por saca de $60 \mathrm{~kg}$. Poucos componentes de produção diferiram do sistema de produção com BRS Estilo. De acordo com produtores, os fatores que mais diferem entre a BRS Embaixador e a BRS Estilo são: a maior quantidade de nitrogênio exigido pela cultivar BRS Embaixador, em torno de 30\% a mais; o maior preço das sementes da BRS Embaixador (aumento de até 100\%), devido ao tamanho maior que o carioca e, logo, a necessidade de usar uma maior quantidade no plantio; e, redução de até 5\% do custo com irrigação devido ao ciclo da cultivar BRS Embaixador ser mais curto, classificada como semiprecoce (75-84 dias), enquanto a BRS Estilo possui um ciclo normal (85-95 dias).

Os valores dos componentes da produção e equivalência do produto, em saca de 60 $\mathrm{kg}$, estão apresentados na tabela 4.

O custeio do pré-plantio, que também compreendeu a aplicação de calcário, terraceamento para conservação do solo, dessecação para limpeza da área, valor de mão de obra e operações com máquinas, totalizou $\mathrm{R} \$ 403,84$ por hectare, mesmo valor do custeio do pré-plantio do sistema de produção com a cultivar BRS Estilo. Entretanto, esse valor representa 7,06\% do custo de produção do sistema de produção com a cultivar BRS Embaixador, e valor equivalente a $\mathrm{R} \$ 2,56$ por saca de $60 \mathrm{~kg}$. 
Tabela 4: Custo de produção de feijão-comum por hectare, com o cultivar BRS Embaixador, na $3^{\mathrm{a}}$ safra, em Goiás, safra 2018.

\begin{tabular}{|c|c|c|c|}
\hline Insumos/Operações/Serviços & $\begin{array}{c}\text { Custo atual } \\
\left(\mathbf{R} \$ . \mathrm{ha}^{-1}\right)\end{array}$ & Participação (\%) & $\begin{array}{c}\text { Equivalência } \\
\text { (sc.60 kg) }\end{array}$ \\
\hline Calagem & 176,93 & 3,09 & 1,12 \\
\hline Terraceamento & 32,65 & 0,57 & 0,21 \\
\hline Dessecação & 194,26 & 3,40 & 1,23 \\
\hline Plantio & $2.228,27$ & 38,98 & 14,12 \\
\hline Tratos Culturais & $1.693,90$ & 29,63 & 11,19 \\
\hline Colheita & 944,95 & 16,53 & 5,99 \\
\hline Pós-colheita & 194,74 & 3,41 & 1,23 \\
\hline Custos Financeiros Adicionais & 251,38 & 4,40 & 1,59 \\
\hline CUSTO TOTAL & $5.717,07$ & 100,00 & 36,23 \\
\hline
\end{tabular}

Fonte: Elaboração própria.

Notas: Com base no preço (FOB) recebido pelo produtor de feijão, Porto de Paranaguá, pela saca de 60 quilogramas, em setembro de $2018=\mathrm{R} \$ 157,80$.

Com base nos preços médios de fatores de produção recebidos pelos produtores em Goiás, na primeira semana do mês de abril de 2018.

No plantio foram gastos $\mathrm{R} \$ 2.228,27$ por hectare, ou seja, um valor equivalente a $\mathrm{R} \$$ 14,12 por saca de $60 \mathrm{~kg}$, representando $38,98 \%$ do custo total de produção do sistema. O plantio compreendeu as mesmas atividades que o sistema com BRS Estilo, as quais são o tratamento de sementes, adubação com NPK, operações com máquinas, mão de obra e sementes. Porém, os gastos com fertilizantes e sementes foram maiores.

Nos tratos culturais ou condução da lavoura, foram gastos R $\$ 1.693,90$ por hectare, do custo de produção do sistema. A condução da lavoura se deu com as mesmas atividades que o sistema de produção com BRS Estilo, a saber: controle de formigas, plantas daninhas, pragas e doenças, adubação de cobertura, irrigação, mão de obra e operações com máquinas. A diferença está na quantidade de irrigação, com uso de 5,0\% a menos, e na quantidade de adubação de cobertura que, para grãos especiais, é de $30 \%$ a mais. O custeio dos tratos culturais representa $29,63 \%$ do valor do custo total, ou seja, é equivalente a R\$ 11,19 por saca de $60 \mathrm{~kg}$.

A colheita mecanizada, o custo com mão de obra e a quantidade de sacaria totalizaram $\mathrm{R} \$ 944,95$ por hectare, representando $16,53 \%$ do custo total de produção do sistema, ou o equivalente a $\mathrm{R} \$ 5,99$ por saca de $60 \mathrm{~kg}$. Já, o transporte da produção da propriedade ao armazém e o armazenamento dos grãos, totalizaram $\mathrm{R} \$ 104,74$ por hectare, sendo equivalente a $\mathrm{R} \$ 1,19$ por saca de $60 \mathrm{~kg}$, ou $3,41 \%$ do custo total do sistema de produção. Apesar de serem praticadas as mesmas atividades do sistema de produção com BRS Estilo, os valores se alteram por influência da quantidade de sacarias utilizadas. Os custos adicionais financeiros são os mesmos com Proagro, assistência técnica, juros e INSS. Porém, para o sistema com BRS Embaixador, os custos adicionais financeiros representam $4,40 \%$ do custo total, ou valor equivalente a $\mathrm{R} \$ 1,59$ por saca de $60 \mathrm{~kg}$. 
Destacamos que não foram encontradas pesquisas sobre os custos de produção deste tipo de cultivar para que se pudesse fazer um comparativo. Contudo, vale ressaltar que, na pesquisa realizada por Nascente et al. (2012) foram apontadas variações produtivas entre os diferentes tipos de grãos especiais.

Assim como já verificado na pesquisa realizada com o cultivar BRS Estilo, os insumos também foram os componentes que mais oneraram o custo total do sistema em análise, com gasto de $\mathrm{R} \$ 3.272,94$, o que representa $57,25 \%$. O custo com as operações com máquinas foi o segundo componente que mais onerou o custo total $(27,32 \%)$, seguido pelo custo com irrigação $(5,02 \%)$, custos adicionais financeiros $(4,40 \%)$, pós-colheita $(3,41 \%)$ e mão de obra $(2,61 \%)$. Os componentes com seus respectivos valores e percentuais estão apresentados na tabela 5 .

Tabela 5: Custos dos componentes do processo produtivo de feijão-comum, com o cultivar BRS Embaixador, por hectare, na 3a safra, em Goiás, safra 2018.

\begin{tabular}{l|c|c}
\hline \hline \multicolumn{1}{c|}{ Componentes da Produção } & Custo Atual (R\$.ha-1) & Participação (\%) \\
\hline Insumos & $3.272,94$ & 57,25 \\
\hline Operações com máquinas & $1.561,73$ & 27,32 \\
\hline Irrigação & 287,16 & 5,02 \\
\hline Serviços com mão-de-obra & 149,13 & 2,61 \\
\hline Custos adicionais financeiros & 251,38 & 4,40 \\
\hline Pós-colheita & 194,74 & 3,41 \\
\hline CUSTO TOTAL & $\mathbf{5 . 7 1 7 , 0 7}$ & $\mathbf{1 0 0 , 0 0}$ \\
\hline \hline
\end{tabular}

Fonte: Dados da pesquisa.

Dos insumos, as sementes têm maior representatividade nos custos, cerca de 48,42\% do total dos insumos. Em seguida, os fertilizantes e corretivos com $24,44 \%$, depois, os agrotóxicos com $23,40 \%$ e, por fim, as sacarias com 3,72\%. Os insumos com seus respectivos valores e participação estão apresentados na tabela 6 .

Tabela 6: Custos dos insumos do processo produtivo de feijão-comum, com o cultivar BRS Embaixador, por hectare, na $3^{\text {a }}$ safra, em Goiás, safra 2018.

\begin{tabular}{l|c|c}
\hline \multicolumn{1}{c|}{ Insumos } & Custo Atual (R\$.ha-1) & Participação (\%) \\
\hline Agrotóxicos & 766,05 & 23,40 \\
\hline Fertilizantes e Corretivos & 800,01 & 24,44 \\
\hline Sementes & $1.584,91$ & 48,42 \\
\hline Sacarias & 121,97 & 3,72 \\
\hline CUSTO TOTAL & $\mathbf{3 . 2 7 2 , 9 4}$ & $\mathbf{1 0 0 , 0 0}$ \\
\hline \hline
\end{tabular}

Fonte: Dados da pesquisa. 
Os resultados verificados em relação aos insumos com maior custo foram diferentes daquele identificado com a cultivar BRS Estilo. Aqui, o maior custo é as sementes, o que pode ser justificado pela maior resistência deste cultivar em relação a pragas e doenças, o que diminui a necessidade de defensivos, fertilizantes e corretivos, além de uma maior produtividade.

\subsubsection{Sistema de produção com BRS Executivo}

O custo de produção do sistema irrigado com o cultivar BRS Executivo, em Goiás, foi estabelecido conforme as fases de implantação e manejo da cultura. O custo médio, por hectare, foi de $\mathrm{R} \$ 5.608,41$, equivalente a $\mathrm{R} \$ 34,20$ por saca de $60 \mathrm{~kg}$. Parte do processo produtivo é semelhante ao sistema de produção com BRS Embaixador e, em partes, ao sistema com BRS Estilo. O pré-plantio, plantio e custos financeiros são os mesmos valores da produção com BRS Embaixador, diferenciando-se nas participações percentuais e na equivalência por sacas com $60 \mathrm{~kg}$. Isto pode ser verificado na tabela 7 , juntamente com os valores dos tratos culturais, colheita e pós-colheita.

Tabela 7: Custo de produção de feijão-comum por hectare, com o cultivar BRS Executivo, na $3^{\text {a }}$ safra, em Goiás, safra 2018.

\begin{tabular}{|c|c|c|c|}
\hline Insumos/Operações/Serviços & $\begin{array}{c}\text { Custo atual } \\
\left(\mathbf{R} \$ . \mathbf{h a}^{-1}\right)\end{array}$ & $\begin{array}{c}\text { Participação } \\
(\%)\end{array}$ & $\begin{array}{c}\text { Equivalência } \\
\text { (sc.60 kg) }\end{array}$ \\
\hline Calagem & 176,93 & 3,15 & 1,08 \\
\hline Terraceamento & 32,65 & 0,58 & 0,20 \\
\hline Dessecação & 194,26 & 3,46 & 1,18 \\
\hline Plantio & $2.228,27$ & 39,73 & 13,59 \\
\hline Tratos Culturais & $1.709,01$ & 30,47 & 10,86 \\
\hline Colheita & 897,28 & 16,00 & 5,47 \\
\hline Pós-colheita & 118,63 & 2,12 & 0,72 \\
\hline Custos Financeiros Adicionais & 251,38 & 4,48 & 1,53 \\
\hline CUSTO TOTAL & $5.608,41$ & 100,00 & 34,20 \\
\hline
\end{tabular}

Fonte: Elaboração própria.

Notas: Com base no preço (FOB) recebido pelo produtor de feijão, Porto de Paranaguá, pela saca de 60 quilogramas, em setembro de $2018=\mathrm{R} \$ 164,00$. Com base nos preços médios de fatores de produção recebidos pelos produtores em Goiás, na primeira semana do mês de abril de 2018.

Os tratos culturais ou condução da lavoura se diferenciam do valor do sistema de produção com BRS Embaixador devido à quantidade de irrigação que a cultivar BRS Executivo necessita. Trata-se de uma cultivar de ciclo normal (85-95 dias) e, por isso, o gasto com irrigação é o mesmo demandado no sistema de produção com BRS Estilo (R\$ $302,27)$, o que resulta em R $\$ 1.709,01$ por hectare do custeio com tratos culturais. Este valor representa $30,47 \%$ do custo total ou valor equivalente a 10,86 por saca de $60 \mathrm{~kg}$. 
O custo com a colheita, transporte da produção e armazenamento dos grãos, é determinado pela quantidade de sacarias utilizadas. A colheita totalizou em $\mathrm{R} \$ 897,28$ por hectare, representando $16,0 \%$ do custo total de produção do sistema ou valor equivalente a 5,47 por saca de $60 \mathrm{~kg}$. A pós-colheita totalizou $\mathrm{R} \$ 118,63$ por hectare, sendo equivalente a 0,72 por saca de $60 \mathrm{~kg}$ ou $2,12 \%$ do custo total.

Estudos voltados para os custos de produção deste cultivar também não foram encontrados, sendo possível verificar um menor custo que o BRS Embaixador. No estudo realizado por Nascente et al. (2012), o que se verifica de destaque é o uso do potássio, como elemento de produtividade, o que talvez, possa ser considerado como uma possibilidade de tornar a atividade ainda mais viáveis.

Os insumos foram novamente verificados como os componentes que mais oneraram o custo total do sistema em análise, com gastos de $\mathrm{R} \$ 3.225,27$, o que representa 57,51\%. $\mathrm{O}$ custo com as operações com máquinas foi o segundo componente que mais onerou o custo total, representando 27,85\%. Em seguida, apresentou-se o custo com irrigação $(5,39 \%)$, os custos adicionais financeiros $(4,48 \%)$, a mão de obra $(2,66 \%)$ e a pós-colheita $(2,12 \%)$. Os componentes com seus respectivos valores e percentuais estão apresentados na tabela 8 .

Tabela 8: Custos dos componentes do processo produtivo de feijão-comum, com o cultivar BRS Executivo, por hectare, na $3^{\text {a }}$ safra, em Goiás, safra 2018.

\begin{tabular}{l|c|c}
\hline \multicolumn{1}{c|}{ Componentes da Produção } & Custo Atual $\left(\mathbf{R} \mathbf{\text { .haa }} \mathbf{- 1}^{\mathbf{1}}\right)$ & Participação (\%) \\
\hline Insumos & $3.225,27$ & 57,51 \\
\hline Operações com máquinas & $1.561,73$ & 27,85 \\
\hline Irrigação & 302,27 & 5,39 \\
\hline Serviços com mão-de-obra & 149,13 & 2,66 \\
\hline Custos adicionais financeiros & 251,38 & 4,48 \\
\hline Pós-colheita & 118,63 & 2,12 \\
\hline CUSTO TOTAL & $\mathbf{5 . 6 0 8 , 4 1}$ & $\mathbf{1 0 0 , 0 0}$ \\
\hline \hline
\end{tabular}

Fonte: Dados da pesquisa.

A análise deste cultivar também demonstrou maiores custos dos insumos com a aquisição das sementes, que tem uma representatividade de 49,14\% do total dos custos dos insumos. Em seguida, identificaram-se os fertilizantes e corretivos com 24,80\%, os agrotóxicos com $23,75 \%$ e as sacarias com 2,30\%. Os insumos com seus respectivos valores e participação estão apresentados na tabela 9. 
Tabela 9: Custos dos insumos do processo produtivo de feijão-comum, com o cultivar BRS Executivo, por hectare, na $3^{\text {a }}$ safra, em Goiás, safra 2018.

\begin{tabular}{l|c|c}
\hline \multicolumn{1}{c|}{ Insumos } & Custo Atual $\left(\mathbf{R} \mathbf{\$ . h a} \mathbf{- 1}^{\mathbf{1}}\right)$ & Participação (\%) \\
\hline Agrotóxicos & 766,05 & 23,75 \\
\hline Fertilizantes e Corretivos & 800,01 & 24,80 \\
\hline Sementes & $1.584,91$ & 49,14 \\
\hline Sacarias & 74,30 & 2,30 \\
\hline CUSTO TOTAL & $\mathbf{3 . 2 2 5 , 2 7}$ & $\mathbf{1 0 0 , 0 0}$ \\
\hline \hline
\end{tabular}

Fonte: Dados da pesquisa.

Não é possível utilizar a justificativa apresentada no cultivar BRS Embaixador em relação à resistência e produtividade, visto que a própria Embrapa (2017a) apresenta classificação SI (Sem Informação) em relação ao cultivar BRS Executivo. Contudo, considerando os dados, o uso de fertilizantes e corretivos não aparece em destaque.

\subsubsection{Sistema de produção com BRS Ártico}

O custo de produção do sistema irrigado com a cultivar BRS Ártico, em Goiás, foi estabelecido conforme as fases de implantação e manejo da cultura. O custo médio, por hectare, foi de $R \$ 5.672,80$, equivalente a 34,59 por saca de $60 \mathrm{~kg}$. Neste sistema, as atividades também são semelhantes ao sistema de produção com BRS Embaixador e, em partes, ao sistema com BRS Estilo. As diferenças de valores estão na colheita e pós-colheita e podem ser verificados na tabela 10 , juntamente com os valores dos demais componentes de produção.

O custo com a colheita, transporte da produção e armazenamento dos grãos, como citado no item anterior, é determinado pela quantidade de sacarias utilizadas. A colheita totalizou em $\mathrm{R} \$ 927,90$ por hectare, representando $16,36 \%$ do custo total de produção do sistema, ou valor equivalente a 5,66 por saca de $60 \mathrm{~kg}$. A pós-colheita totalizou $\mathrm{R} \$ 167,52$ por hectare, sendo equivalente a 1,02 por saca de $60 \mathrm{~kg}$ ou 2,95\% do custo total.

Assim como os demais grãos especiais analisados neste estudo, também não foram encontrados estudos específicos sobre os custos de produção deste cultivar. Porém, na reportagem da pesquisadora do Instituto Agronômico do Paraná (IAPAR), Vânia Moda Cirino (em 2017), este cultivar foi apontado como uma alternativa para a diversificação do plantio e também como um potencial produto para exportação (CIRINO, 2017). Mas, de acordo com a pesquisadora, a produção destes grãos é limitada pela falta de tecnologias e pela falta de organização de cooperativas capazes de passar as orientações necessárias para os produtores. Trata-se de um cultivar com o ciclo bastante precoce (65 a 70 dias) e com alto potencial produtivo de $2.500 \mathrm{~kg}$ por hectare. 
Tabela 10: Custo de produção de feijão-comum por hectare, com o cultivar BRS Ártico, na $3^{\mathrm{a}}$ safra, em Goiás, safra 2018.

\begin{tabular}{|c|c|c|c|}
\hline Insumos/Operações/Serviços & $\begin{array}{c}\text { Custo atual } \\
\left(\mathbf{R} \$ . \mathrm{ha}^{-1}\right)\end{array}$ & $\begin{array}{c}\text { Participação } \\
(\%)\end{array}$ & $\begin{array}{c}\text { Equivalência } \\
\text { (sc.60 kg) }\end{array}$ \\
\hline Calagem & 176,93 & 3,12 & 1,08 \\
\hline Terraceamento & 32,65 & 0,58 & 0,20 \\
\hline Dessecação & 194,26 & 3,42 & 1,18 \\
\hline Plantio & $2.228,27$ & 39,28 & 13,59 \\
\hline Tratos Culturais & $1.693,90$ & 29,86 & 10,86 \\
\hline Colheita & 927,90 & 16,36 & 5,66 \\
\hline Pós-colheita & 167,52 & 2,95 & 1,02 \\
\hline Custos Financeiros Adicionais & 251,38 & 4,43 & 1,53 \\
\hline CUSTO TOTAL & $5.672,80$ & 100,00 & 34,59 \\
\hline
\end{tabular}

Fonte: Elaboração própria.

Notas: Com base no preço (FOB) recebido pelo produtor de feijão, no Porto de Paranaguá, pela saca de 60 quilogramas, em setembro de $2018=\mathrm{R} \$ 164,00$. O preço é referente ao feijão vermelho devido a indisponibilidade de preços de venda do feijão branco. Com base nos preços médios de fatores de produção recebidos pelos produtores em Goiás, na primeira semana do mês de abril de 2018.

Os resultados em relação aos insumos não foram diferentes dos outros cultivares estudados neste estudo, sendo os componentes que mais oneraram o custo total do sistema em análise com gasto de $\mathrm{R} \$ 3.255,89$, o que representa $57,40 \%$. O custo com as operações com máquinas foi o segundo componente que mais onerou o custo total $(27,53 \%)$. Os demais foram: custo com irrigação $(5,06 \%)$, custos adicionais financeiros $(4,43 \%)$, mão de obra $(2,63 \%)$ e pós-colheita $(2,95 \%)$. Os componentes com seus respectivos valores e percentuais estão apresentados na tabela 11. Já, os insumos com seus respectivos valores e participação estão na tabela 12 .

Tabela 11: Custos dos componentes do processo produtivo de feijão-comum, com o cultivar BRS Ártico, por hectare, na $3^{\mathrm{a}}$ safra, em Goiás, safra 2018.

\begin{tabular}{l|c|c}
\hline \hline \multicolumn{1}{c|}{ Componentes da Produção } & Custo Atual (R\$.ha-1) & Participação (\%) \\
\hline Insumos & $3.255,89$ & 57,40 \\
\hline Operações com máquinas & $1.561,73$ & 27,53 \\
\hline Irrigação & 287,16 & 5,06 \\
\hline Serviços com mão-de-obra & 149,13 & 2,63 \\
\hline Custos adicionais financeiros & 251,38 & 4,43 \\
\hline Pós-colheita & 167,52 & 2,95 \\
\hline CUSTO TOTAL & $\mathbf{5 . 6 7 2 , 8 0}$ & $\mathbf{1 0 0 , 0 0}$ \\
\hline \hline
\end{tabular}

Fonte: Dados da pesquisa.

Como é possível observar, na tabela 12, as sementes foram os componentes que mais oneraram o custo total de insumos, representando 48,68\%. Este dado confirma que todos 
os grãos especiais estudados apresentaram as sementes como os maiores custos, em contraponto ao feijão carioca (BRS Estilo), que apresentou como maior custo os fertilizantes/corretivos. Em seguida, os custos do BRS Ártico são os fertilizantes e corretivos com $24,57 \%$, os agrotóxicos com $23,53 \%$ e as sacarias com 3,22\%.

Tabela 12: Custos dos insumos do processo produtivo de feijão-comum, com o cultivar BRS Ártico, por hectare, na $3^{\text {a }}$ safra, em Goiás, safra 2018.

\begin{tabular}{l|c|c}
\hline \multicolumn{1}{c|}{ Insumos } & Custo Atual $\left(\mathbf{R} \mathbf{\$ . h a ^ { - 1 }}\right)$ & Participação (\%) \\
\hline Agrotóxicos & 766,05 & 23,53 \\
\hline Fertilizantes e Corretivos & 800,01 & 24,57 \\
\hline Sementes & $1.584,91$ & 48,68 \\
\hline Sacarias & 104,92 & 3,22 \\
\hline CUSTO TOTAL & $\mathbf{3 . 2 5 5 , 8 9}$ & $\mathbf{1 0 0 , 0 0}$ \\
\hline \hline
\end{tabular}

Fonte: Dados da pesquisa.

\subsection{Análise dos indicadores de eficiência econômica}

Nesta etapa, são analisados os indicadores de eficiência econômica em relação a cada cultivar estudado até o momento, com vistas a realizar um comparativo, considerando o feijão-carioca como um grupo controle. A tabela 13 mostra o cultivar de feijão carioca e os de grãos especiais, com seus respectivos indicadores econômicos e unidades de referência.

Tabela 13: Indicadores de eficiência econômica do processo produtivo de feijãocomum, com os cultivar BRS Estilo, BRS Embaixador, BRS Executivo e BRS

Ártico, por hectare, na $3^{\text {a }}$ safra, em Goiás, safra 2018.

\begin{tabular}{l|c|c|c|c|c}
\hline \hline \multirow{2}{*}{$\begin{array}{c}\text { Indicador } \\
\text { Econômico }\end{array}$} & \multirow{2}{*}{ Unidade } & \multicolumn{4}{|c}{ Sistema de Produção } \\
\cline { 3 - 6 } & BRS Estilo & $\begin{array}{c}\text { BRS } \\
\text { Embaixador }\end{array}$ & $\begin{array}{c}\text { BRS } \\
\text { Executivo }\end{array}$ & $\begin{array}{c}\text { BRS } \\
\text { Ártico }\end{array}$ \\
\hline Produtividade & sc. $60 \mathrm{~kg} \mathrm{ha}^{-1}$ & 52,00 & 40,35 & 24,58 & 34,71 \\
\hline $\begin{array}{l}\text { Custo de } \\
\text { produção }\end{array}$ & $\mathrm{R} \$ \mathrm{ha}^{-1}$ & $4.562,14$ & $5.717,07$ & $5.608,41$ & $5.672,80$ \\
\hline RB & $\mathrm{R} \$ \mathrm{ha}^{-1}$ & $5.319,60$ & $6.367,23$ & $4.031,12$ & $5.692,44$ \\
\hline $\mathrm{RL}$ & $\mathrm{R} \$ \mathrm{ha}^{-1}$ & 757,46 & 650,19 & $-1.577,29$ & 19,64 \\
\hline $\mathrm{PN}$ & $\mathrm{sc} .60 \mathrm{~kg} \mathrm{ha}^{-1}$ & 44,60 & 36,23 & 34,20 & 34,59 \\
\hline PTF & - & 1,17 & 1,11 & 0,72 & 1,00 \\
\hline TR & $\%$ & 0,17 & 0,11 & $-0,28$ & 0,00 \\
\hline \hline
\end{tabular}

Fonte: Dados da pesquisa.

Notas: Preço $(F O B)$ do cultivar BRS Estilo $=$ R $\$ 102,30$. Preço $(F O B)$ do cultivar BRS Embaixador $=$ R $\$$ 157,80. Preço (FOB) do cultivar BRS Executivo $=164,00$. Preço $(\mathrm{FOB})$ do cultivar BRS Ártico $=\mathrm{R} \$ 164,00$.

O sistema de produção de feijão carioca com o cultivar BRS Estilo resultou em uma receita bruta de $\mathrm{R} \$ 5.319,60$ por hectare, com custo de produção de $\mathrm{R} \$ 4.562,14 \mathrm{ha}^{-1}$. Com 
isto, gerou em uma renda líquida positiva igual a $\mathrm{R} \$ 757,46$, revelando que o sistema em análise é viável economicamente, ao preço considerado. O ponto de nivelamento, com o atual nível de preço, indica que o sistema se torna inviável economicamente com uma produção abaixo de 44,60 sacas de $60 \mathrm{~kg} \mathrm{ha}^{-1}$. A produtividade total de fatores resultou em 1,17 , indicando ser viável o sistema, já que a cada $R \$ 1,00$ gasto gera $R \$ 1,17$ de receita bruta. A taxa de retorno de $17 \%$ corrobora a viabilidade, indicando que a cada $\mathrm{R} \$ 1,00$ gasto no processo produtivo obtém-se $\mathrm{R} \$ 0,17$ de renda líquida adicional.

No sistema de produção de feijão com o cultivar BRS Embaixador, a receita bruta foi de $\mathrm{R} \$ 6.367,23$ por hectare, com custo de produção $\mathrm{R} \$ 5.717,07 \mathrm{ha}^{-1}$. A renda líquida neste sistema resultou em $\mathrm{R} \$ 650,19$, revelando que o sistema é viável economicamente, ao preço considerado. O ponto de nivelamento, com o atual nível de preço, é 36,23 sacas de $60 \mathrm{~kg} \mathrm{ha}^{-1}$, abaixo deste valor o sistema se torna inviável economicamente. A produtividade total de fatores foi de 1,11, indicando novamente que o sistema é viável economicamente, e que a cada $R \$ 1,00$ gasto gera $R \$ 1,11$ de receita bruta. Com a taxa de retorno de $11 \%$, a produção é viável, indicando que a cada $\mathrm{R} \$ 1,00$ gasto são gerados $\mathrm{R} \$$ 0,11 de renda líquida adicional.

O sistema de produção de feijão com o cultivar BRS Executivo totalizou R \$ 4.031,12 de renda bruta, com custo de produção de $\mathrm{R} \$ 5.608,41$, gerando uma renda líquida negativa de $\mathrm{R} \$-1.577,29$, tornando o sistema produtivo inviável economicamente, ao preço considerado. A produtividade total de fatores igual a 0,72 e a taxa de retorno igual a $-0,28$ confirmam a inviabilidade. Para se tornar economicamente viável, o sistema de produção teria que gerar uma produtividade mínima de 34,20 sacas de $60 \mathrm{~kg} \mathrm{ha}^{-1}$, que é o valor do ponto de nivelamento, o que significa que o sistema teria que aumentar no mínimo 9,62 sacas de $60 \mathrm{~kg} \mathrm{ha}^{-1}$, com o atual nível de preço, para cobrir pelo menos o custo de produção.

O sistema de produção de feijão com o cultivar BRS Ártico teve uma renda bruta de $\mathrm{R} \$ 5.692,44$, com custo de produção $R$ \$ 5.672,80, e renda líquida $R$ \$ 19,64, indicando que o sistema é viável economicamente, ao preço considerado. Entretanto a produtividade total de fatores foi igual ao mínimo considerado para que o sistema se sustente, ou seja, 1,00. A taxa de retorno igual a $0 \%$, mostrando que o sistema não gera ganhos e nem perdas - mas, pode ser que a atividade se torne inviável ao longo do tempo. O ponto de nivelamento foi de 34,59, praticamente o mesmo valor da produtividade do cultivar, de 35,71. Isto explica o fato do valor da receita cobrir apenas o custo de produção, gerando um valor baixo de renda líquida. Este sistema com BRS Ártico é estável e tem possibilidade de expansão, mas é preciso aumentar a produtividade para que ao longo do tempo se sustente.

Em relação à produtividade, o BRS Embaixador é o que apresenta resultado mais próximo à BRS Estilo, fator já verificado na pesquisa de Nascente et al. (2012). Trata-se do cultivar mais produtivo entre os grãos especiais, seguido do BRS Ártico e do BRS Executivo. Em relação aos custos de produção, a BRS Executivo apresentou leve vantagem em relação aos demais cultivares de grãos especiais, todavia, também foi o que apresentou pior resultado em relação à renda líquida $(-1.577,29)$ e à taxa de retorno $(-0,28 \%)$, demonstrando ser a produção com menos eficiência econômica. Deste modo, o BRS Embaixador foi o que mostrou maior eficiência econômica em relação aos cultivares 
estudados, com $0,11 \%$ de taxa de retorno, resultado mais próximo do BRS Estilo, que foi de $0,17 \%$.

\section{Conclusão}

A partir dos resultados verificados neste estudo foi possível alcançar o objetivo do mesmo, identificando que a viabilidade agroeconômica da produção dos grãos especiais, em Goiás, aos preços considerados, na terceira safra, é encontrada no cultivar BRS Embaixador.

O sistema de produção com o cultivar BRS Embaixador teve o custo de produção de $\mathrm{R} \$ 5.717,07$, e que, ao preço de venda considerado, gerou uma renda líquida positiva de $\mathrm{R} \$ 650,19$, e taxa de retorno de $11 \%$. O sistema de produção com a cultivar BRS Executivo teve um custo de produção de $\mathrm{R} \$ 5.608,41$. Mas, ao preço considerado, resultou em renda líquida negativa de $-\mathrm{R} \$ 1.577,29 \mathrm{e}$, consequentemente, uma taxa de retorno negativa de $28 \%$, o que tornou o sistema inviável economicamente. Já, o sistema de produção com a cultivar BRS Ártico, com custo de produção de R\$ 5.672,80, é viável economicamente ao preço considerado. Porém, a renda líquida gerada é considerada baixa, em torno de $\mathrm{R} \$$ 19,64, e a taxa de retorno nula. Por isso, este cultivar não se apresenta como a melhor opção para os produtores, já que possui uma perspectiva incerta.

Assim sendo, é possível afirmar que a hipótese de que a produção de grãos especiais de feijão é agroeconomicamente viável foi validada apenas para o cultivar BRS Embaixador (grãos vermelhos escuros graúdos - ou Dark Red Kidney - DRK). Não foi possível validar a hipótese para os grãos do cultivar BRS Executivo (feijão rajado) e do cultivar BRS Ártico (feijão branco).

Para que os sistemas de produção, nas condições deste estudo, com os cultivares BRS Executivo e BRS Ártico se tornem atrativos é necessário que estudos futuros procurem melhorar os componentes técnicos e econômicos ou mesmo criar outros para que os cultivares se adaptem adequadamente. É interessante também que os programas de melhoramento genético invistam em pesquisas para que os cultivares de grãos especiais tenham maior produtividade, além de pesquisas para que os mesmos possam ser cultivados nas outras safras em Goiás. Isto resultará em maior diversificação da produção e do consumo de feijão.

\section{Referências}

ALVES, Thiago. Avaliação na administração pública: uma proposta de análise para as escolas públicas de educação básica. Tese de Doutorado. Universidade de São Paulo, 2007.

ARAÚJO, Hilda Silva; SABBAG, Omar Jorge; LIMA, Bruno Tadeu Marotta; ANDRIGHETTO, Cristiana; RUIZ, Urbano dos Santos. Aspectos econômicos da produção 
de bovinos de corte. Pesquisa Agropecuária Tropical, v. 42, n. 1, p. 82-89, 2012. https://doi.org/10.1590/S1983-40632012000100012

BARBOSA FILHO, Fernando de Holanda; PESSÔA, Samuel de Abreu; VELOSO, Fernando A. Evolução da produtividade total dos fatores na economia brasileira com ênfase no capital humano - 1992-2007. Revista Brasileira de Economia, v. 64, n. 2, p. 91-113, 2010. https://doi.org/10.1590/S0034-71402010000200002

CIRINO, Vania Moda. Feijão branco é alternativa para diversificação de plantio e com potencial demanda para exportação. Iapar avança nas pesquisas. Notícias Agrícolas. 2017. Disponível em: <https://www.noticiasagricolas.com.br/videos/feijao-e-graosespeciais/194361-ao-vivo-mercado-do-feijao-branco.html\#.XGIwMjBKiM8>. Acesso em: 04 fev. 2019.

CONAB, Companhia Nacional de Abastecimento. Acompanhamento de safra brasileira grãos. Observatório Agrícola. v. 6 Safra 2018/19 - Quarto levantamento, Brasília, p. 1126, janeiro 2019.

DOLL, John P., ORAZEM, F. Production Economics: Theory with applications. Tradução e adaptação José Carlos da Silva Medeira dos Santos. New York: John Wiley \& Sons, 1984.

EMBRAPA - Empresa Brasileira de Pesquisa Agropecuária. Balanço Social da Embrapa. Relatório institucional de impacto socioeconômico e ambiental da cultivar feijão BRS Estilo. In: SIDE/Embrapa Sede/SGI/Embrapa Arroz e Feijão, 2017. Disponível em: <http://bs.sede.embrapa.br/2017/relatorios/arrozefeijao_2017_feijaobrsestilo.pdf>.

Acesso em: 12 set. 2018.

EMBRAPA - Empresa Brasileira de Pesquisa Agropecuária. Catálogo de Cultivares de Feijão Comum 2016-2017. 2.ed. 2017a. Disponível em: <https://www.embrapa.br/buscade-publicacoes/-/publicacao/1062715/catalogo-de-cultivares-de-feijao-comum>. Acesso em: 02 ago. 2018.

GITMAN, Lawrence J. Princípios da Administração Financeira. 12 ed. São Paulo: Pearson Prentice Hall, 2010.

GODINHO, Vicente de Paulo Campos; UTUMI, Marley Marico; OLIVEIRA, Samuel José de Magalhães. Estimativa de custos de produção de soja em Rondônia - safra 2001/2002. Porto Velho: Embrapa Rondônia, 2001 (Embrapa Rondônia. Comunicado Técnico, 191).

GUIDUCCI, Rosana do Carmo Nascimento; LIMA FILHO, Joaquim Raimundo de; MOTA, Mierson Martins. Viabilidade Econômica de Sistemas de Produção Agropecuários: metodologia e estudos de caso. Brasília, DF: Embrapa, 2012.

KAY, Ronald D.; EDWARDS, William M.; DUFFY, Patricia A. Gestão de propriedades rurais. 7.ed. Porto Alegre, RS: AMGH Editora, 2014. 
LAZZARINI NETO, S. Controle da produção e custos. São Paulo: SDF Editores, 1995. LIMA, José Donizetti de; TRENTIN, Marcelo Gonçalves; OLIVEIRA, Gilson Adamczuk; BATISTUS, Dayse Regina; SETTI, Dalmarino. A systematic approach for the analysis of the economic viability of investment projects. International Journal of Engineering Management and Economics. v. 5, n. 1/2, p. 19-34, 2016. https://doi.org/10.1504/IJEME.2015.069887

LOPES, Marcos Aurélio; CARVALHO, Francisval de Melo. Custo de produção do gado de corte. Lavras: UFLA, v. 47, 2002.

MARTINS, Eliseu. Contabilidade de Custos. São Paulo: Altas, 2006.

MARTIN, Nelson Batista; SERRA, Renata; OLIVEIRA, Marli Dias Mascarenhas; ÂNGELO, José Alberto; OKAWA, Hiroshige. Sistema integrado de custos agropecuários - CUSTAGRI. Informações Econômicas, São Paulo, v. 28, n. 1, p. 7-28, 1998.

MENEGATTI, Ana Laura Angeli. Custo de produção para soja convencional e transgênica à luz das metodologias utilizadas pelos órgãos públicos no Brasil e nos Estados Unidos: um estudo para o estado do Mato Grosso do Sul. Dissertação de Mestrado - USP, Escola Superior de Agricultura Luiz de Queiroz. 2006. https://doi.org/10.11606/D.11.2006.tde-03102006-171619

NASCENTE, Adriano Stephan; KLUTHCOUSKI, João; CRUSCIOL, Carlos Alexandre Costa; COBUCCI, Tarcísio; OLIVEIRA, Priscila de. Fertilization of common bean cultivars in tropical lowlands. Pesquisa Agropecuária Tropical, v. 42, n. 4, p. 407-415, 2012. https://doi.org/10.1590/S1983-40632012000400003

OAIGEN, Ricardo Pedroso; BARCELOS, Julio Otávio Jardim; CHRISTOFARI, Luciana Fagundes; CASTRO, Emilio Eduardo Cura; CANOZZI, Maria Eugênia Andrighetto. Custos de produção em terneiros de corte: uma revisão. Veterinária em Foco, v. 3, n. 2, p. 169-180, 2006.

OLIVEIRA, Marli Dias Mascarenhas; VEIGA FILHO, Alceu de Arruda; VEGRO, Celso Luis Rodrigues; MATTOSINHO, Paulo Sérgio Vianna. Análise de Custos, Rentabilidade e de Investimentos na Produção de Café Cereja Descascado: Estudo de Caso. In: Congresso da Sociedade Brasileira de Economia e Sociologia Rural, 43. 2005.

RESENDE, Marcio de Araújo; SIQUEIRA, Jose Ricardo Maia de. As indústrias de pequeno porte e o orçamento de capital: um estudo sobre análise de investimentos na Baixada Fluminense. Pensar Contábil, v. 9, n. 38, p. 1-15, 2004.

SANTOS, Gilberto José dos; MARION, José Carlos. Administração de custos na agropecuária. 2. ed. São Paulo: Atlas, 1996.

SILVA, Aluísio Goulart; WANDER, Alcido Elenor; BARBOSA, Flávia Rabelo; DE OLIVEIRA GONZAGA, Augusto César; DA SILVA, José Geraldo. Análise econômica da produção de feijão comum em sistema de produção convencional e de produção 
integrada, em Cristalina, Estado de Goiás, e Unaí, Estado de Minas Gerais, maio de 2009 a abril de 2010. Informações Econômicas, São Paulo, v. 42, n. 5, p. 55-64, 2012.

SILVA, Osmira Fátima da; WANDER, Alcido Elenor. Viabilidade econômica da cultivar de feijão-comum BRS Estilo. Revista Brasileira de Desenvolvimento Regional, Blumenau, v. 3, n. 1, p. 223-242, 2015. https://doi.org/10.7867/23175443.2015V3N1P223-242

SILVEIRA, Marina Aparecida da. Percepção da competitividade da produção e comercialização de feijão pela agricultura familiar no estado de Goiás. 2015. $183 \mathrm{f}$. Dissertação (Mestrado em Agronegócio) - Universidade Federal de Goiás, Goiânia, 2015.

SOLOMON, Ezra. Teoria da Administração Financeira. Rio de Janeiro: Zahar, 1973.

TSUNECHIRO, Alfredo; OLIVEIRA, Marli Dias Mascarenhas; FURLANETO, F. D. P. B.; DUARTE, A. P. Análise técnica e econômica de sistemas de produção de milho safrinha, região do médio Paranapanema, estado de São Paulo. Informações Econômicas, v. 36, n. 9, p. 62-70, 2006.

VIEIRA, Euselia Paveglio. Custos e formação do preço de venda. 2. ed. Ijuí: Ed. Unijuí, 2013. 